\title{
Traditional Indigenous System
}

National Cancer Institute

\section{Source}

National Cancer Institute. Traditional Indigenous System. NCI Thesaurus. Code C15889.

Subcategory of Alternative Medical Systems in CAM. This sub-category refers to major indigenous systems of medicine other than acupuncture and traditional oriental medicine. It includes systems such as Ayurvedic medicine, Native American Medicine, Unani-T ibbi, Kampo, Traditional African systems and community based traditional medical systems. This sub-category may become subdivided further as these systems become better studied and more familiar in the U.S. Included are: Native American Medicine, Ayurvedic Medicine, Unani-T ibbi, SADHU, Kampo Medicine, Traditional African Medicine, Traditional Aborig inal Medicine, Curandersimo, Central and South American practices, Psychic surgery. 